\title{
Usefulness of NT-pro BNP monitoring to identify echocardiographic responders following cardiac resynchronization therapy
}

\author{
Julien Magne, Michelle Dubois, Jean Champagne, Jean G Dumesnil, \\ Philippe Pibarot, François Philippon, Gilles O'Hara and Mario Sénéchal*
}

Address: Institut Universitaire de Cardiologie et de Pneumologie de Québec, Department of Cardiology, Quebec, Canada

Email: Julien Magne - mario.senechal@criucpq.ulaval.ca; Michelle Dubois - michelle.dubois@criucpq.ulaval.ca; Jean Champagne - mario.senechal@criucpq.ulaval.ca; Jean G Dumesnil - mario.senechal@criucpq.ulaval.ca; Philippe Pibarot - mario.senechal@criucpq.ulaval.ca; François Philippon - mario.senechal@criucpq.ulaval.ca; Gilles O'Hara - mario.senechal@criucpq.ulaval.ca; Mario Sénéchal* - mario.senechal@criucpq.ulaval.ca

* Corresponding author

Published: 20 August 2009

Cardiovascular Ultrasound 2009, 7:39 doi:10.1/86/1476-7/20-7-39
Received: 4 June 2009

Accepted: 20 August 2009

This article is available from: http://www.cardiovascularultrasound.com/content/7/I/39

(c) 2009 Magne et al; licensee BioMed Central Ltd.

This is an Open Access article distributed under the terms of the Creative Commons Attribution License (http://creativecommons.org/licenses/by/2.0), which permits unrestricted use, distribution, and reproduction in any medium, provided the original work is properly cited.

\begin{abstract}
Background: Cardiac resynchronization therapy (CRT) improves left ventricular (LV) volumes, mitral regurgitation (MR) severity and symptoms of patients with heart failure (HF). However, $\geq$ $30 \%$ of patients have no significant clinical or echocardiographic improvement following CRT. Reverse remodeling after CRT correlates with improved clinical outcomes. We hypothesized that in NT-pro BNP monitoring is accurate to identify responders following CRT.

Methods: 42 consecutive patients (mean age $66 \pm 12$ years, male 68\%) with HF undergoing CRT were prospectively enrolled. Responders at follow-up were defined by echocardiography (decrease in LV end systolic volume $\geq 15 \%$ ). Echocardiography and NT-pro BNP measurement were performed at baseline and repeated 3 to 6 month after CRT.

Results: There was no significant difference between responders $(n=29,69 \%)$ and nonresponders $(n=13,31 \%)$ regarding baseline NT-pro BNP level. Responders had significantly higher decrease in NT-pro BNP levels during follow-up than non-responders (absolute: $-1428 \pm 1333$ pg.ml-1 vs. $-6 \mathrm{I} \pm 959$ pg. $\mathrm{ml}^{-1}, \mathrm{p}=0.002$; relative: $-45 \pm 28 \%$ vs. $2 \pm 28 \%$, $\mathrm{p}<0.000 \mathrm{I}$ ). A decrease of $\geq 15 \%$ in NT-pro BNP 3-6 months after CRT identifies echocardiographic responders with a sensitivity of $90 \%$ and a specificity of $77 \%$.
\end{abstract}

Conclusion: NT-pro BNP monitoring can accurately identify echocardiographic responders after CRT.

\section{Background}

Cardiac resynchronization therapy (CRT) is established as a valuable additive treatment for patients with drugrefractory heart failure (HF) and electromechanical asynchrony. CRT improves left ventricular (LV) function and geometry, exercise capacity and outcomes of appropriately selected patients with HF [1-4]. CRT also leads to a decrease in both resting and exercise mitral regurgitation severity $[5,6]$ by enhancement of LV function and local synchronicity (i.e. mechanical activation of papillary 
muscle insertion sites) [7]. Remodeling is a predictor of cardiovascular mortality in patients with congestive HF $[1,2]$. Reverse remodeling through pharmacological intervention and CRT correlates with improved clinical outcomes [6]. An important issue in CRT is the problem of non-responders. Using clinical criteria, rate of non response to CRT are estimated to be $20-30 \%$, but in studies using objective parameters of LV remodeling, CRT non-responder rate reaches $40-50 \%$ [8]. Brain natriuretic peptides (BNP) and its inactive aminoterminal portion (NT-pro BNP), are neurohormones released by the ventricle in response to increase LV wall stress. Hence, BNP level may have valuable role for the assessment of cardiac dysfunction, particularly LV dysfunction, and for the monitoring of the response to cardiac therapy $[9,10]$. Recently, Fruhwald et al[11] showed that CRT leads to an early and sustained decrease in NT-pro BNP potentially reflecting improvement in LV function. In responders, left lateral wall pacing increases systolic function, reduces mitral regurgitation (MR) and thus decrease the wall motion stress. In this favorable remodeling process, neurohumoral activity is reduced and the decrease in plasma Btype natriuretic peptide after initiation of CRT predicts clinical improvement during follow-up [12]. We hypothesized that NT-pro BNP reduction following CRT correlates with $\mathrm{LV}$ remodeling and MR improvement and that change in NT-pro BNP following CRT can identify echocardiographic responders with good accuracy.

\section{Methods}

From May 2005 to March 2008, 42 consecutive patients referred for CRT with chronic HF were prospectively enrolled. Inclusion criteria were as follow: (1) NYHA functional class $\geq$ III, (2) QRS duration $\geq 120 \mathrm{~ms}$, (3) chronic LV systolic dysfunction defined as LV ejection fraction (LVEF) $\leq 35 \%$, (4) LV dyssynchrony $\geq 50 \mathrm{~ms}$, (5) optimal medical treatment for HF including angiotensinconverting enzyme inhibitors or AT1 receptor antagonists diuretics, beta-receptor blockers and spironolactone when tolerated, and (6) sinus rhythm. Patients with recent myocardial infarction ( $<6$ months), coronary revascularization procedure ( $<6$ months) and presenting standard contraindications to DSE were excluded. This study complies with the "Declaration of Helsinki" and all patients provided informed consent. The study protocol was approved by local ethics committee.

\section{Protocol}

Patients were submitted to clinical examination, 12-lead electrocardiography (EKG), blood sampling, transthoracic echocardiography (TTE), and dobutamine stress echocardiography (DSE) within one week before CRT. Additionally, TTE and blood sampling were also performed within the week and at 3 to 6 month following CRT.

\section{Doppler echocardiography and DSE}

Two-dimensional and Doppler TTE examination were performed with commercially available echocardiographic systems (Sonos 5500 or 7500, Philips Medical Systems, Amsterdam, The Netherlands). Dopplerechocardiographic measurements included LV enddiastolic and end-systolic diameters and LVEF determined by modified biplane Simpson method. LV outflow tract stroke volume was calculated by multiplying LV outflow tract area by LV outflow tract velocity-time integral measured by pulsed wave Doppler. Proximal isovelocity surface area (PISA) method was used to quantify both mitral regurgitation volume (RV) and effective regurgitant orifice (ERO) area as recommended by The American Society of Echocardiography guideline [13]. Quantification of interventricular asynchronism was obtained by recording aortic and pulmonary Doppler flows with pulsed wave, from the apical four-chamber and parasternal short-axis views respectively. Aortic and pulmonary ejection delays were defined as the delay between the onset of the QRS complex on the surface EKG and the onset of the aortic and pulmonary waves. Intraventricular asynchronism measurement was assessed with tissue Doppler imaging (TDI) from apical views to evaluate longitudinal myocardial regional function, analyzing septal, inferior, lateral, anterior and posterior walls. Velocity profiles were recorded with a sample volume placed in the middle of the basal segment of each LV wall. TDI signals were recorded at a sweep of $100 \mathrm{~mm} / \mathrm{s}$. Intraventricular asynchronism was defined as the time difference between the shortest and longest electromechanical delay among the five LV walls [14]. Responders were defined as a post-CRT decrease in LV end-systolic volume $\geq 15 \%$ at the 3-6 months followup echocardiography [14]. The wall motion score index (WMSI) was quantified at rest and during DSE, using a 16segment model as recommended [13]. DSE was performed according to a low-dose infusion protocol. Patients received 5, 10, 15, and $20 \mu \mathrm{g} / \mathrm{kg} / \mathrm{min}$ of dobutamine in 3-minutes stages, with echocardiographic images recorded at the end of each stage. The presence of $\mathrm{LV}$ contractile reserve (CR) was defined as an improvement of $\geq 0.20$ in WMSI (rest-DSE). Heart rate and blood pressure were monitored during each stage. Criteria for stopping dobutamine infusion were (1) hypotension (systolic blood pressure < $90 \mathrm{mmHg}$ ), (2) angina, (3) significant arrhythmias (atrial fibrillation, bigeminy, ventricular tachycardia), (4) achievement of $85 \%$ maximal predicted heart rate.

\section{CRT implantation}

A coronary sinus venogram was obtained using balloon catheter, followed by the insertion of the LV pacing lead. An SF guiding catheter was used to position the LV lead (Guidant Corporation, St Paul, NM or Medtronic Inc, Minneapolis, MN) in the coronary sinus. 
The preferred position was lateral or postero-lateral vein. Right atrial and ventricular leads were positioned conventionally. All leads were connected to a dual-chamber biventricular ICD (Guidant Corporation, or Medtronic Inc).

\section{Blood sampling and NT-pro BNP measurement}

Venous blood samples were withdrawn from an antecubital vein into chilled ethylene-diamine-tetra-acetic acid Vacutainer test tubes after 20 minutes of rest with patients in a supine position. Samples were placed immediately on ice-cold water and the tubes were then centrifuged at 4000 r.p.m. at $4^{\circ} \mathrm{C}$ for $15 \mathrm{~min}$. Supernatant plasma was then immediately aliquoted into labelled cryo-vials. NT-pro BNP was determined by a commercially available electrochemiluminescence immunoassay based on a polyclonal antibody-based sandwich chemiluminescence assay (Roche Diagnostics, Germany) using an autoanalyser (Elecsys 2010).

\section{Statistical analysis}

Continuous variables are expressed as mean \pm SD or mean \pm SEM when specified. Patients were separated into 2 groups (responders and non-responders). Baseline data for responders versus non-responders groups were compared for statistical significance using t-test or chi-square test, as appropriate. Baseline and post-CRT Dopplerechocardiographic data were analyzed using a 2-way analysis of variance for repeated measurements to assess the effects of time (baseline vs. post-CRT) and group (nonresponders vs. responders). Linear regression analyses were used to evaluate the relationship between changes in NT-pro BNP and changes in echocardiographic parameters. Sensitivity and specificity for identification of CRT responders were determined for various cut-off values of echocardiographic parameters using receiver-operating characteristic (ROC) curves.

Forward and backward multiple stepwise regression were performed to determine the association between the change in NT-pro BNP and LV end-systolic volume after adjustment for baseline variables. Logistic regression was also performed to assess the performance of change in NTpro BNP to identify CRT responders.

\section{Results}

Among the 42 patients included in this study (mean age $66 \pm 12$ years, male 68\%), 29 (69\%) were responders. There was no significant difference between responders and non-responders (Table 1) regarding to age, prevalence of male gender, coronary artery disease, functional NYHA class III or IV and left or right bundle branch block at baseline. Although non-responders had significantly more frequent intraventricular conduction defect than responders $(\mathrm{p}=0.04)$, there was no significant difference between the 2 groups regarding pre-CRT pacing and PR duration (Table 1). No significant difference between groups was found for baseline and post CRT medication at last follow-up.

\section{NT-pro BNP at baseline and follow-up}

The decrease in NT-pro BNP following CRT was higher in responders than in non-responders $(\mathrm{p}=0.002)$ (Figure 1$)$. Baseline mean NT-pro BNP was $3328 \pm 2474$ pg.ml-1 $\left(25 \%\right.$ quartile $=1186 \mathrm{pg} \cdot \mathrm{ml}^{-1}$, median $=2776$ pg. $\mathrm{ml}^{-1}$, $75 \%$ quartile $=5098$ pg.ml- ${ }^{-1}$ ) and was not statistically different between responders and non-responders (Figure 1)

Table I: Baseline demographic and clinical data.

\begin{tabular}{|c|c|c|c|c|}
\hline Variables & All patients $(n=42)$ & Responders ( $n=29,69 \%)$ & Non-Responders $(n=13,31 \%)$ & P Value \\
\hline \multicolumn{5}{|l|}{ Demographic data } \\
\hline Age, years & $66 \pm 12$ & $66 \pm 11$ & $66 \pm 15$ & 0.83 \\
\hline Male, n (\%) & $30(68)$ & $19(65)$ & $10(77)$ & 0.45 \\
\hline CAD, n (\%) & $30(68)$ & $18(62)$ & II (85) & 0.13 \\
\hline \multicolumn{5}{|l|}{ Clinical data } \\
\hline QRS duration, ms & $159 \pm 28$ & $162 \pm 27$ & $155 \pm 30$ & 0.51 \\
\hline LBBB, n (\%) & $27(6 I)$ & $19(65)$ & $6(46)$ & 0.24 \\
\hline RBBB, n (\%) & $2(4.5)$ & $2(7)$ & $0(0)$ & $\ldots$ \\
\hline IVCD, n (\%) & $8(18)$ & $3(10)$ & $5(38)$ & 0.04 \\
\hline $\mathrm{PR}, \mathrm{ms}$ & $180 \pm 40$ & $172 \pm 32$ & $195 \pm 51$ & 0.08 \\
\hline Pre-CRT pacing, n (\%) & $7(16)$ & $5(17)$ & $2(15)$ & 0.88 \\
\hline NYHA III/IV, n (\%) & $31(70) / 13(30)$ & $22(76) / 7(24)$ & $7(54) / 6(46)$ & 0.16 \\
\hline \multicolumn{5}{|l|}{ Medication } \\
\hline Diuretic, n (\%) & 41 (93) & $27(93)$ & $12(92)$ & 0.93 \\
\hline$\beta$-Blockers, n (\%) & $41(93)$ & $26(90)$ & $13(100)$ & 0.13 \\
\hline ACEi, n (\%) & $31(70)$ & $20(69)$ & $10(77)$ & 0.59 \\
\hline AR Blockers, n (\%) & $13(30)$ & $9(32)$ & $3(23)$ & 0.55 \\
\hline Digoxin, n (\%) & II (25) & $5(17)$ & $6(46)$ & 0.06 \\
\hline Spironolactone, n (\%) & $26(59)$ & $15(52)$ & $10(77)$ & 0.12 \\
\hline
\end{tabular}

CAD indicates coronary arteries disease, LBBB, left bundle branch block, RBBB, right bundle branch block, IVCD, intraventricular conduction defect, $A C E i$, angiotensin converting enzyme inhibitors and $A R$, angiotensin receptors. 


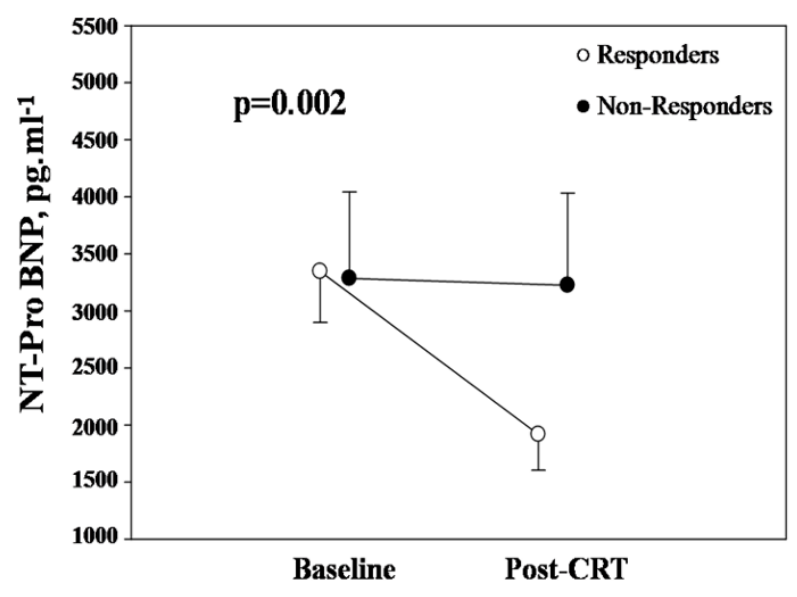

Figure I

Changes in Nt-pro BNP in responders and non responders defined as a decrease $\geq 15 \%$ in $L V$ end systolic volume 3 to 6 months post CRT. Data are expressed as mean \pm SEM.

$\left(3346 \pm 2401 \mathrm{pg} \cdot \mathrm{ml}^{-1}\right.$ and $\left.3286 \pm 695 \mathrm{pg} \cdot \mathrm{ml}^{-1}, \mathrm{p}=0.95\right)$ The change in NT-pro BNP between pre-CRT and 3-6 months post CRT evaluations was significantly more important in responders than in non-responders (absolute: $-1428 \pm 1333$ pg.ml-1 vs. $-61 \pm 959$ pg.ml-1, $\mathrm{p}=0.002$; relative: $-45 \pm 28 \%$ vs. $2 \pm 28 \%$, p < 0.0001). Moreover, there was a definite trend for significant difference between the 2 groups with regards to 3-6 months NT-pro BNP ( $=0.07)$.

\section{Baseline and chronic changes in echocardiographic parameters}

Baseline LV volumes, LVEF, resting LV WMSI, MR severity (i.e. ERO, RV and prevalence of severe MR) and inter and intraventricular asynchronism were not significantly different between responders and non-responders (Table 2). However, non-responder patients had higher baseline LV stroke volume than responders but after CRT this difference was no longer significant. As expected, LV geometry and function as well as MR severity were significantly improved in responders following CRT (Table 2). By definition, patients with response to CRT had better improvement of LV end-systolic volume compared to nonresponders $(-42 \pm 17 \mathrm{ml}$ vs. $13 \pm 24 \mathrm{ml}, \mathrm{p}<0.0001$ and $26 \pm 10 \%$ vs. $-6 \pm 10 \%, \mathrm{p}<0.0001)$.

\section{Contractile Reserve}

CR was present in 30 patients (71\%) and responders had significant higher prevalence of CR than non-responders ( $83 \%$ vs. $46 \%, p=0.02$ ) (Table 2 ). Consistently, the improvement in WMSI during DSE was more important in responders than in non-responders $(13.2 \pm 7.8 \%$ vs. $7.6 \pm 9.2 \%, p=0.048)$. Compared to patients without $C R$, those with CR had significant lower baseline and followup LV end-systolic volume ( $167 \pm 56$ vs. $213 \pm 58 \mathrm{ml}, \mathrm{p}=$ 0.03 and $135 \pm 52$ vs. $207 \pm 83 \mathrm{ml}, \mathrm{p}=0.001$, respectively). They also had higher decrease in LV end-systolic volume following CRT $(-33 \pm 5$ vs. $-6 \pm 9 \mathrm{ml}, \mathrm{p}=0.01)$.

According to the presence of CR, there was no significant difference in baseline and post-CRT NT-pro BNP ( $\mathrm{p}=0.69$ and $\mathrm{p}=0.26)$. Although there was no significant difference in baseline ERO ( $17 \pm 9$ vs. $\left.22 \pm 11 \mathrm{~mm}^{2}, \mathrm{p}=0.22\right)$, patients with CR had lower ERO at follow-up ( $8 \pm 7$ vs. 20 $\left.\pm 14 \mathrm{~mm}^{2}, \mathrm{p}=0.004\right)$ than those without CR.

\section{Relations between changes in MR severity and echocardiographic parameters}

Percent changes in ERO and in RV were correlated with percent changes in LV end-systolic volume (ERO: $r=0.73$, $\mathrm{p}<0.0001$, RV: $\mathrm{r}=0.53, \mathrm{p}=0.0008$ ) (Figure 2) and enddiastolic volumes (ERO: $\mathrm{r}=0.62, \mathrm{p}<0.0001, \mathrm{RV}: \mathrm{r}=0.49$, $\mathrm{p}=0.002$ ) (Figure 3).

However, only the change in ERO was correlated with the peak WMSI and the change in WMSI during DSE $(r=0.39$, $\mathrm{p}=0.018$ and $\mathrm{r}=0.42, \mathrm{p}=0.0098$, respectively.

\section{Relations between changes in NT-pro BNP and echocardiographic parameters}

The percent change in NT-pro BNP correlated with percent change in LVEF $(\mathrm{r}=0.32, \mathrm{p}=0.038)$, LV stroke volume, $(\mathrm{r}=0.31, \mathrm{p}=0.043)$, LV end-diastolic volume $(\mathrm{r}=$ $0.42, \mathrm{p}=0.006)$ and RV $(\mathrm{r}=0.45, \mathrm{p}=0.003)$. The best correlations were found with percent changes in LV endsystolic volume $(\mathrm{r}=0.60, \mathrm{p}<0.0001)$ and ERO $(\mathrm{r}=0.59$, $\mathrm{p}=0.0001$ ) (Figure 4 and 5). Moreover there was also a significant correlation between the percent change in WMSI during dobutamine infusion and percent change in NT-pro BNP ( $\mathrm{r}=0.50, \mathrm{p}=0.0007)$ (Figure 6). Patients with CR had higher changes and percent change in NT-pro BNP than those without CR $(p=0.0093$ and $p=0.0047$, respectively).

\section{Utilization of NT-pro BNP for identification of echocardiographic response to CRT and change in MR severity}

After adjustment for age, change in NT-pro BNP remains correlated with the percent change in LV end-systolic volume $(\mathrm{r}=0.58, \mathrm{p}=0.0001)$. ROC curve analysis, demonstrated that the absolute change in NT-pro BNP is accurate to identify response to CRT (area under curve $=0.82$ ) and that a decrease in BNP $\geq 277$ pg. $\mathrm{ml}^{-1}$ identifies echocardiographic responders (Figure 7 ) with good sensitivity (83\%), specificity (77\%), positive predictive value $(89 \%)$ and negative predictive value (64\%). The percent change in NT-pro BNP was slightly more accurate (area under curve $=0.88$ ) with a sensitivity of $90 \%$, a specificity of 
Table 2: Baseline and late post-CRT Echocardiographic data.

\begin{tabular}{|c|c|c|c|c|}
\hline Variables & All patients $(n=42)$ & Responders $(n=29,69 \%)$ & Non Responders $(n=13,31 \%)$ & P Value \\
\hline \multicolumn{5}{|l|}{ LV geometry and function } \\
\hline \multicolumn{5}{|l|}{ LV end-systolic Volume, $\mathrm{ml}$} \\
\hline Baseline & $177 \pm 65$ & $175 \pm 64$ & $189 \pm 62$ & 0.49 \\
\hline Late post-CRT & $155 \pm 67$ & $133 \pm 57^{*}$ & $198 \pm 67$ & 0.0017 \\
\hline \multicolumn{5}{|l|}{ LV end-diastolic Volume, $\mathrm{ml}$} \\
\hline Baseline & $213 \pm 69$ & $209 \pm 67$ & $228 \pm 67$ & 0.40 \\
\hline Late post-CRT & $201 \pm 73$ & $|8| \pm 66^{*}$ & $239 \pm 72^{*}$ & 0.01 \\
\hline \multicolumn{5}{|l|}{ LV stroke Volume, $\mathrm{ml}$} \\
\hline Baseline & $42 \pm 13$ & $39 \pm 10$ & $50 \pm 13$ & 0.0048 \\
\hline Late post-CRT & $51 \pm 11$ & $51 \pm 9 *$ & $49 \pm 14$ & 0.65 \\
\hline \multicolumn{5}{|l|}{ LV ejection fraction, \% } \\
\hline Baseline & $19 \pm 7$ & $18 \pm 7$ & $19 \pm 7$ & 0.75 \\
\hline Late post-CRT & $24 \pm 9$ & $27 \pm 9 *$ & $18 \pm 6$ & 0.0025 \\
\hline \multicolumn{5}{|l|}{ Wall Motion Score Index } \\
\hline Baseline rest & $3.5 \pm 0.4$ & $3.4 \pm 0.4$ & $3.6 \pm 0.2$ & 0.29 \\
\hline Baseline dobutamine & $3.1 \pm 0.4$ & $3 \pm 0.4 *$ & $3.3 \pm 0.4^{*}$ & 0.038 \\
\hline Contractile Reserve, n (\%) & $30(7 I)$ & $24(83)$ & $6(46)$ & 0.02 \\
\hline \multicolumn{5}{|l|}{ Mitral Regurgitation } \\
\hline \multicolumn{5}{|l|}{ Effective orifice Area, $\mathrm{mm}^{2}$} \\
\hline Baseline & $18 \pm 13$ & $18 \pm 12$ & $17 \pm 14$ & 0.73 \\
\hline Late post-CRT & $10 \pm 11$ & $5 \pm 5^{*}$ & $19 \pm 15$ & $<0.0001$ \\
\hline \multicolumn{5}{|l|}{ Regurgitant Volume, ml } \\
\hline Baseline & $29 \pm 26$ & $31 \pm 29$ & $25 \pm 19$ & 0.54 \\
\hline Late post-CRT & $17 \pm 17$ & $11 \pm 13^{*}$ & $29 \pm 19$ & 0.0009 \\
\hline \multicolumn{5}{|c|}{ Severe Mitral Regurgitation, n (\%) } \\
\hline Baseline & $19(45)$ & $12(4 \mid)$ & $7(54)$ & 0.45 \\
\hline Late post-CRT & $10(61)$ & $2(7)^{*}$ & $8(61)$ & 0.0005 \\
\hline \multicolumn{5}{|l|}{ Asynchronism } \\
\hline Interventricular, ms & $46 \pm 27$ & $46 \pm 30$ & $45 \pm 22$ & 0.92 \\
\hline Intraventricular, ms & $85 \pm 25$ & $85 \pm 25$ & $85 \pm 27$ & 0.93 \\
\hline
\end{tabular}

LV indicates left-ventricular and CRT, cardiac resynchronisation therapy. * significant difference $(p<0.05)$ between baseline and late post-CRT or between rest and dobutamine data; severe mitral regurgitation is defined as an effective orifice area $\geq 20 \mathrm{~mm}^{2}$.

$77 \%$, a positive predictive value of $90 \%$ and a negative predictive value of $75 \%$, for percent decrease NT-pro BNP $\geq 15 \%$ (Figure 8). In multivariate linear regression, after adjustment for age, sex, baseline LVEF and LV end-systolic volume, percent change in NT-pro BNP was independently associated with percent of change in LV end-systolic volume $(\beta=0.43 \pm 0.14, p=0.004)$.

Multivariate logistic regression showed, after adjustment for other baseline variables, that the percent change in NTpro BNP is a good surrogate marker of response to CRT (odds-ratio $=1.08$ (95\% confidence interval: $1.03-1.16$ ) per $1 \%$ of decrease in NT-pro BNP, p =0.008). Similar results were found when adding $\mathrm{CR}$ in the multivariate models. When entering, the change in NT-pro BNP as a dichotomous variable in the multivariate logistic model, an absolute decrease in NT-pro BNP $\geq 277$ pg.ml-1 and a percent decrease of $\geq 15 \%$ were independently associated with a 9.4-fold ( $\mathrm{p}=0.0056)$ and 7.1 -fold $(\mathrm{p}=0.0018)$ increase in the likelihood of positive response to CRT, respectively. Multivariate linear regression also identified the percent change in NT-pro $\mathrm{BNP} \geq 15 \%$, after adjusting for baseline characteristics (i.e. age, sex, ERO and LV endsystolic volume), as strongly associated with the percent change in ERO $(\beta=37 \pm 8.5, p<0.0001)$.

\section{Discussion}

The main finding of our study is that change in NT-pro BNP level between baseline and 3 to 6 months after CRT may be useful to identify (1) echocardiographic responders following CRT and (2) the magnitude of decrease in MR severity following CRT. Our results also confirm that change in MR severity after CRT implantation is related to the improvement in LV geometry. Furthermore, previous studies found that baseline LV viability is a strong predictor of LV performance following CRT [12-14]. Hence, correlation between the change in LV WMSI during DSE and the change in NT-pro BNP (Figure 4), emphasized by our data, suggests that a substantial amount of recruitable myocardium is needed to obtain improvement in $\mathrm{LV}$ function and MR and thus decrease in NT-pro BNP after CRT. Consistently, we also confirmed results from previous studies showing that the presence of CR is a good predictor [15-17] of response to CRT. 


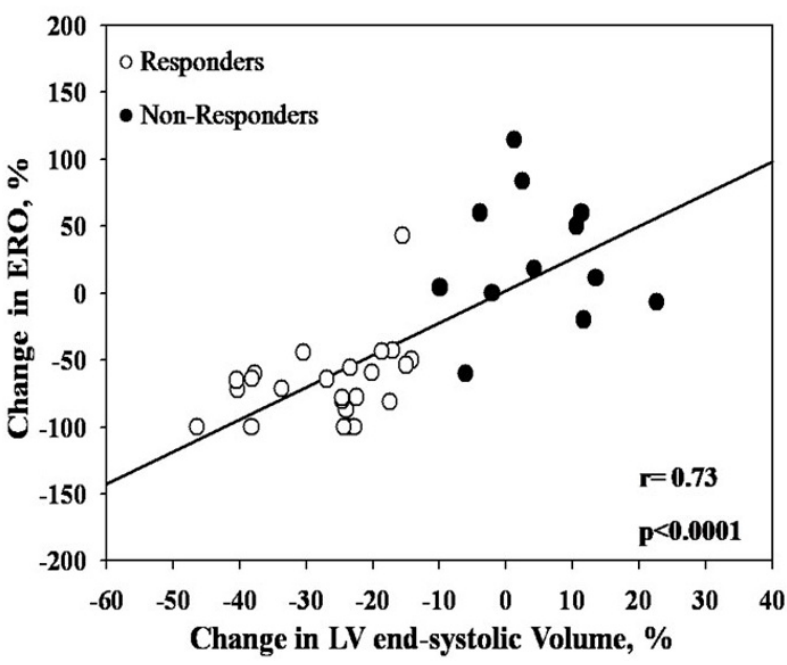

Figure 2

Correlation between changes in effective regurgitant orifice (ERO) area and changes in LV end-systolic volumes.

\section{Cardiac resynchronization therapy and brain natriuretic peptide}

Several previous studies reported a significant decrease in natriuretic peptide following CRT implantation [8, 18-24]. Recently, Fruhwald et al. [11] demonstrated, in patients with moderate or severe HF and LV dyssynchrony, that CRT exerts an early and sustained reduction in NT-pro $\mathrm{BNP}$ reflecting the improvements in LV geometry and

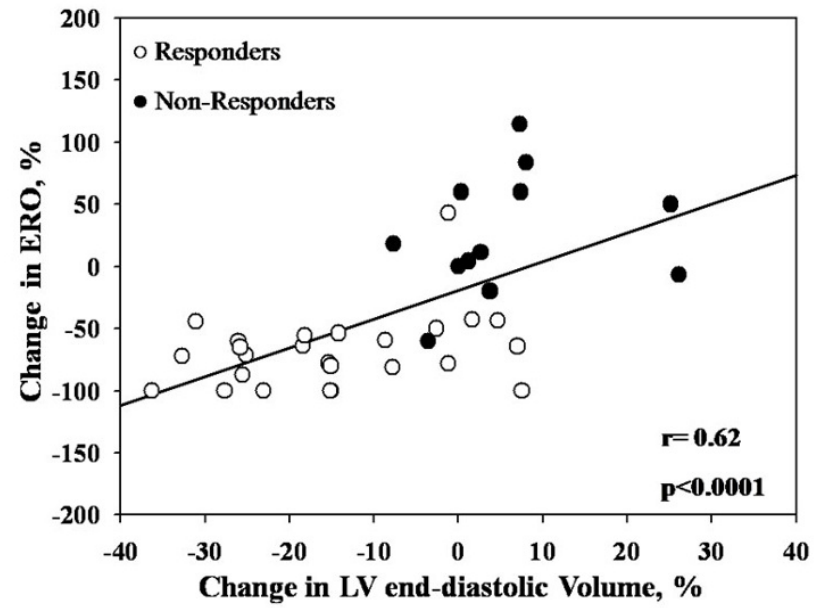

Figure 3

Correlation between changes in effective regurgitant orifice (ERO) area and changes in LV end-diastolic volumes.

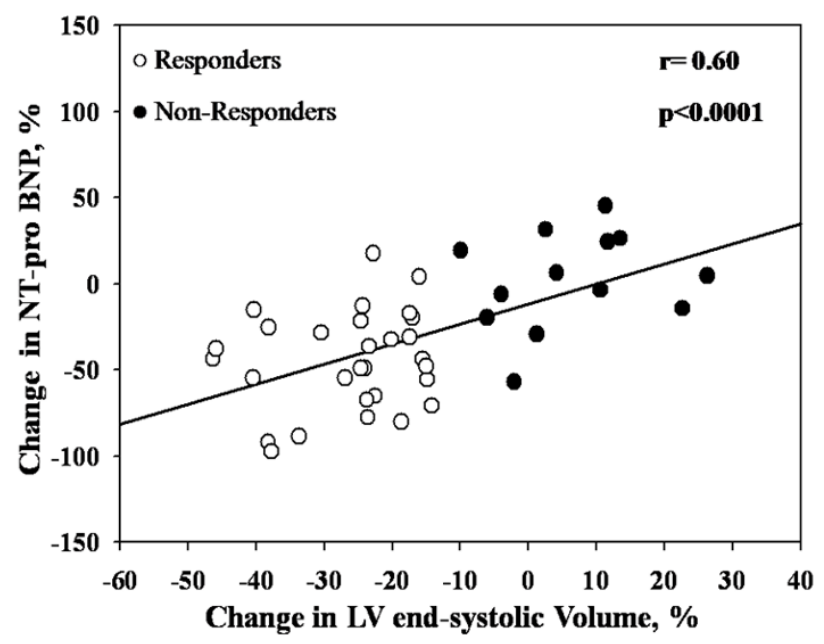

Figure 4

Correlation between changes in NT-pro BNP and changes in LV end-systolic volume.

function. Moreover, the Care-HF post-hoc analysis concluded that NT-pro BNP may be used to monitor CRT effect. Consistently, Kubanek et al[18] found similar results and reported that a decrease in $\mathrm{BNP}>6.7 \%$ between baseline and 3 months follow-up is accurate to differentiate responders from non-responders patients (specificity $=77 \%$ and sensibility $=90 \%$ ). Importantly and in accordance with other studies, our results suggest that baseline neurohumoral activities do not predicts the effect of CRT. Indeed, response to CRT [25] is clearly a multifactor process including the severity of intraventricular asynchrony, presence and localisation of LV viability,

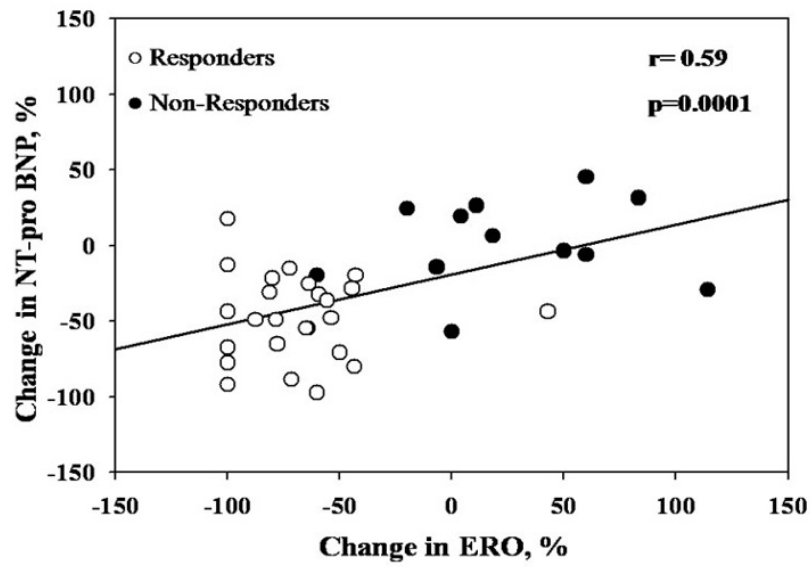

Figure 5

Correlation between changes in NT-pro BNP and changes in effective regurgitant orifice (ERO) area. 


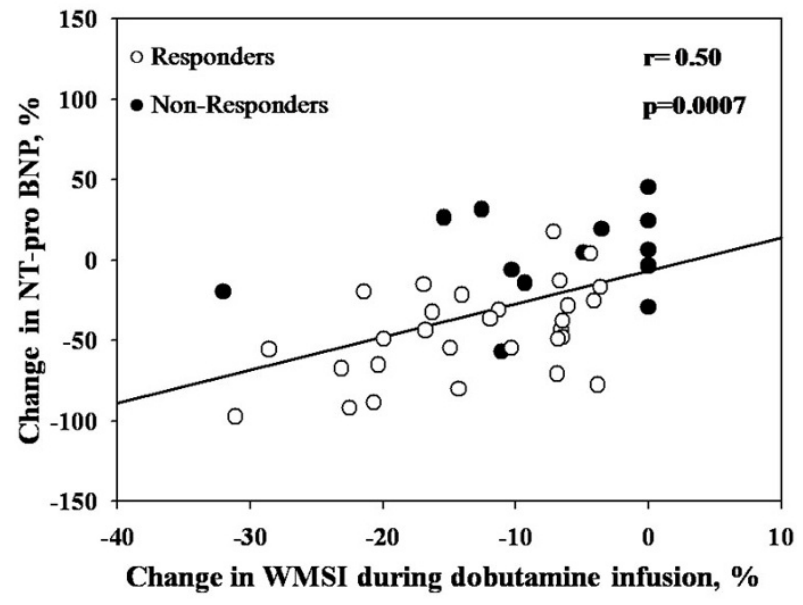

Figure 6

Correlation between changes in NT-pro BNP and changes in LV wall motion score index (WMSI) during dobutamine stress echocardiography.

and lead placement with respect to the latest LV activation site. In contrast, NT-pro BNP release is essentially determined by LV wall stress. Hence, it is not surprising that baseline NT-pro BNP is not accurate to predict clinical or echocardiographic response after CRT.

Mechanism of changes in NT-pro BNP following CRT Mechanism underlying CRT benefit in patients with HF is related to reduction of LV dyssynchrony and correspond-

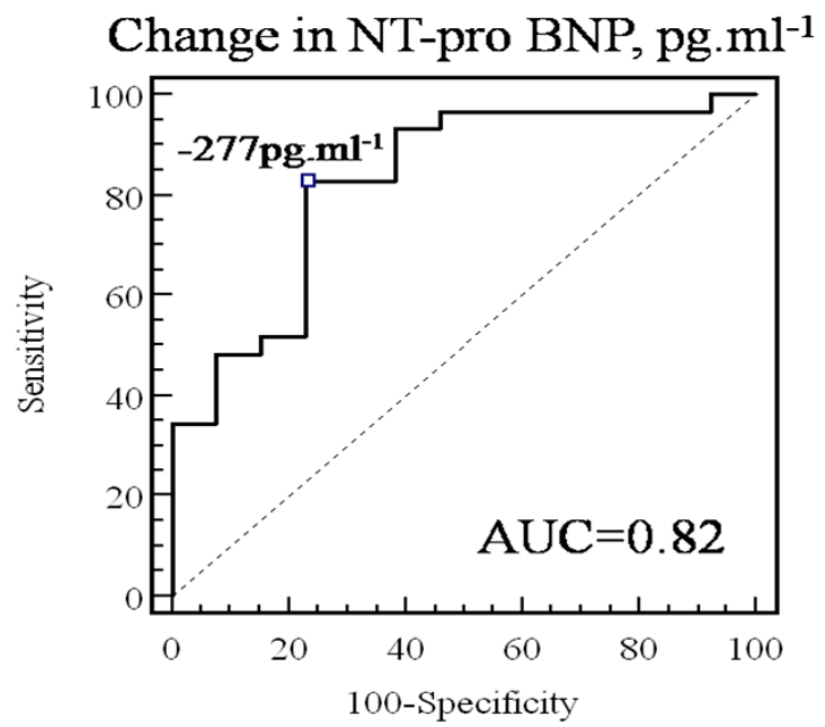

Figure 7

Receiver-operating characteristic (ROC) curves analysing the accuracy of absolute changes in NT-pro BNP to identify CRT response.

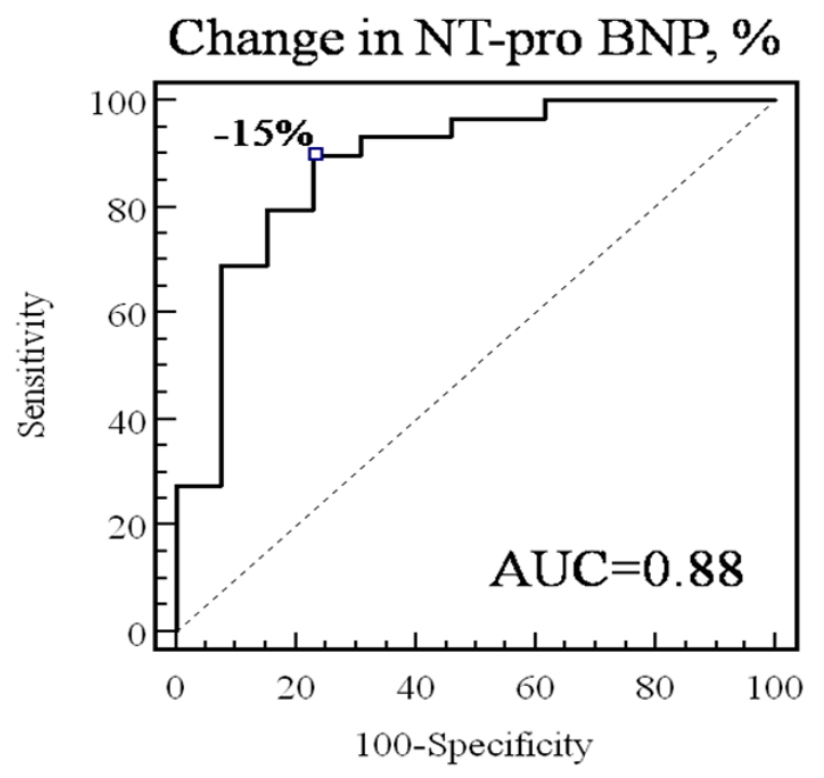

Figure 8

Receiver-operating characteristic (ROC) curves analysing the accuracy of relative changes in NT-pro BNP to identify CRT response.

ing stress-strain disparities and inefficient ventricle contraction. Ultimately, CRT significantly improves both LV function and geometry. This effect results in a decrease in mitral valve tethering and in a concomitant increase in mitral closing forces which, in turn, lead to significant improvement of MR severity. Furthermore, because electrical conduction and regional wall thickening are influenced by the extent of myocardial fibrosis, it has been hypothesized that long-term response to CRT could correlate with myocardial viability in patients with LV dysfunction.

Using nuclear myocardial perfusion imaging (2C1Ti), magnetic resonance imaging, and DSE, several studies have demonstrated the importance of LV viability in predicting response to CRT [26-32]. In accordance with these studies, our results suggest that LV remodeling and decrease in natriuretic peptides post CRT seem to be, at least in part, determined by the presence and extent of myocardial viability. In summary, NT-pro BNP can rapidly drop when cardiac therapy provides significant improvement in LV geometry and function. Obviously, the impact of CRT on both LV and MR is the basic mechanism involved in the change in NT-pro BNP.

\section{Contractile reserve and response to $C R T$}

Several recent studies had underlined the crucial role of myocardial CR to allow LV reverse remodeling[15,16,29] and clinical improvement[17] following CRT. Moonen et 
al. [15] showed that response to CRT mainly depends not only on the extent of LV dyssynchrony and MR severity but also on the presence of CR. In addition, CR may be useful to predict CRT response, evaluated either with DSE [33] or with exercise echocardiography $[15,16]$. Our results confirm that CR is essential to reach satisfactory LV reverse remodeling and response to CRT and that NT pro BNP is an accurate surrogate marker of LV improvement following CRT.

\section{Clinical implications}

BNP is widely considered as useful marker for the diagnosis and prognosis of HF and may be helpful to guide medical management. The presence of high plasma BNP levels is associated with an increased risk of cardiac events and death in patients with chronic HF. The titration of HF treatment based on the reduction of plasma NT-pro BNP concentrations has been found to be superior to treatment with empirical trial-based therapy dictated by clinical judgment. NT-pro BNP is routinely used in patients with HF and is an accurate marker of LV and clinical status.

Recently, Miller et al. [34] found in a prospective series of 172 ambulatory HF patients that a significant increase in BNP was associated with markedly reduced event-free survival. However, only large decrease of BNP concentrations led to outcome improvement. More modest increases or decreases seem to confer little additional predictive value.

Furthermore, our results showed that NT-pro BNP is also a good surrogate marker to identify LV remodeling and MR reduction following CRT. More importantly, NT-pro BNP monitoring allows the clinician to accurately identify echocardiographic responders to CRT. Since LV remodeling predicts outcome with better accuracy than clinical improvement after CRT [35] and that NT-pro BNP monitoring can identify echocardiographic responders with a very good sensitivity and specificity, assessment of NT pro-BNP after CRT could be used as an additional tool to assist the clinician in the evaluation of the patient's condition (additional file 1 and 2). The main finding of this study is that $\mathrm{LV}$ remodeling can be identified by change in neurohormone level early (3-6 months) after CRT. Patients identified as non responders may be followed more closely. This subgroup of patients may have a different clinical management: re-evaluation of coronary-sinus lead position, programming of timing intervals, shorter time periods between follow-up evaluations, cardiac transplantation or other surgical options.

\section{Limitation}

The main limitation of this study is the relatively the small number of patients, which reduced the statistical power for multivariate analyses. In addition, the studied population had various LV dysfunction etiologies, including ischemic and non-ischemic myocardial dysfunction. Nevertheless, this also underlines that NT-pro BNP is reliable even in heterogeneous population of CRT patients. Dyssynchrony was defined by longitudinal TDI using a cut-off value of $50 \mathrm{~ms}$ on as inclusion criterion. Combining longitudinal and radial dyssynchrony index as inclusion criterion could have been helpful in choosing a more homogenous population prone to CRT response.

\section{Conclusion}

Results of this study show that NT-pro BNP monitoring can accurately identify echocardiographic responders after CRT. Decrease in NT-pro BNP $\geq 15 \%$ during follow-up is a good surrogate marker of favourable LV remodeling and MR reduction following CRT. Monitoring of NT-pro BNP may be useful for the management of patients with HF and CRT.

\section{Competing interests}

The authors declare that they have no competing interests.

\section{Authors' contributions}

MS is the principal investigator, he conceived the study and participated in its design and coordination, he participated in the interpretation of the results and he drafts the manuscript; JM performed the statistical analysis, participated in the interpretation of the results and drafts the manuscript; MD participated in data collection, coordination of the study and helped to draft the manuscript; JC participated in the implantation of CRT and in the interpretation of pulmonary $\mathrm{X}$ rays for localization of CRT lead; JGD participated to interpreted the results and in the preparation of the manuscript, PP participate in the preparation of the manuscript; FP participated in the implantation of CRT; GO participated in the implantation of CRT; All authors read and approved the final manuscript.

\section{Additional material}

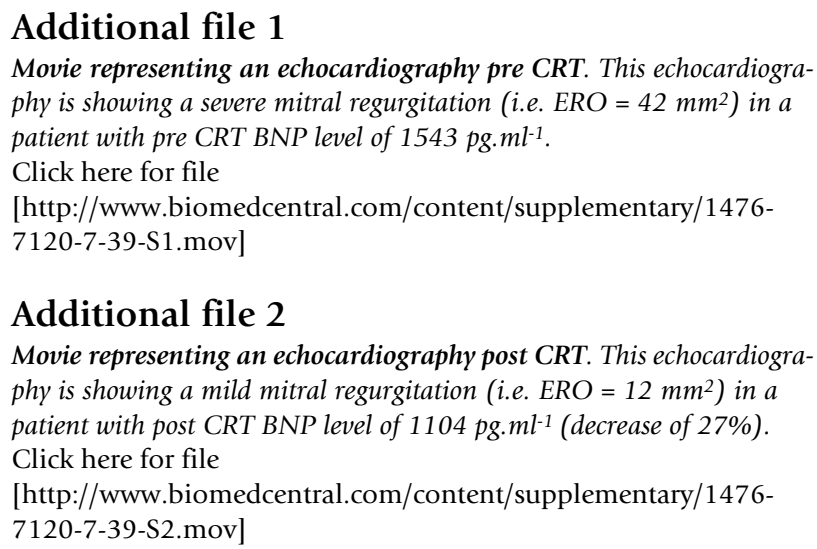




\section{Acknowledgements}

Dr Mario Sénéchal is recipient of a Grant from Institut de Cardiologie de Québec.

We thank Dr Louis Blier and Dr Frank Molin for their assistance in the CRT implantation and their participation in the study. We also thank the IUCPQ echocardiography technologists, and Gabrielle Labrecque, nurse, for their help in data collection.

\section{References}

I. Cleland JG, Daubert JC, Erdmann E, Freemantle N, Gras D, Kappenberger $L$, et al:: The effect of cardiac resynchronization on morbidity and mortality in heart failure. N Engl J Med 2005, 352: $1539-1549$.

2. Abraham WT, Fisher WG, Smith AL, Delurgio DB, Leon AR, Loh E, et al:: Cardiac resynchronization in chronic heart failure. $N$ Engl J Med 2002, 346: I845-1853.

3. Linde C, Leclercq C, Rex S, Garrigue S, Lavergne T, Cazeau S, et al:: Long-term benefits of biventricular pacing in congestive heart failure: results from the MUltisite STimulation in cardiomyopathy (MUSTIC) study. J Am Coll Cardiol 2002, 40: III-II8.

4. Bristow MR, Saxon LA, Boehmer J, Krueger S, Kass DA, De Marco T, et al: Cardiac-resynchronization therapy with or without an implantable defibrillator in advanced chronic heart failure. $N$ Engl J Med 2004, 350:2 I 40-2I 50.

5. Lancellotti P, Melon P, Sakalihasan N, Waleffe A, Dubois C, Bertholet $M$, et al: Effect of cardiac resynchronization therapy on functional mitral regurgitation in heart failure. Am J Cardiol 2004, 94: |462-|465.

6. Madaric J, Vanderheyden M, Van Laethem C, Verhamme K, Feys A, Goethals $M$, et al.: Early and late effects of cardiac resynchronization therapy on exercise-induced mitral regurgitation: relationship with left ventricular dyssynchrony, remodelling and cardiopulmonary performance. Eur Heart J 2007.

7. Kanzaki H, Bazaz R, Schwartzman D, Dohi K, Sade LE, Gorcsan J III: A mechanism for immediate reduction in mitral regurgitation after cardiac resynchronization therapy: insights from mechanical activation strain mapping. J Am Coll Cardiol 2004, 44:1619-1625.

8. Piepoli MF, Villani GQ, Corra U, Aschieri D, Rusticali G: Time course of effects of cardiac resynchronization therapy in chronic heart failure: benefits in patients with preserved exercise capacity. Pacing Clin Electrophysiol 2008, 3 I :70 I-708.

9. Troughton RW, Frampton CM, Yandle TG, Espiner EA, Nicholls MG, Richards AM: Treatment of heart failure guided by plasma aminoterminal brain natriuretic peptide (N-BNP) concentrations. Lancet 2000, 355: I I26-I I30.

10. Murdoch DR, McDonagh TA, Byrne J, Blue L, Farmer R, Morton J], et al.: Titration of vasodilator therapy in chronic heart failure according to plasma brain natriuretic peptide concentration: randomized comparison of the hemodynamic and neuroendocrine effects of tailored versus empirical therapy. Am Heart J 1999, I38: | |26-I|32.

II. Fruhwald FM, Fahrleitner-Pammer A, Berger R, Leyva F, Freemantle $N$, Erdmann E, et al.: Early and sustained effects of cardiac resynchronization therapy on $\mathbf{N}$-terminal pro-B-type natriuretic peptide in patients with moderate to severe heart failure and cardiac dyssynchrony. Eur Heart J 2007, 28: I 592-I 597.

12. de Groote P, Dagorn J, Soudan B, Lamblin N, McFadden E, Bauters C: $B$-type natriuretic peptide and peak exercise oxygen consumption provide independent information for risk stratification in patients with stable congestive heart failure. J Am Coll Cardiol 2004, 43: I584-I589.

13. Zoghbi WA, Enriquez-Sarano M, Foster E, Grayburn PA, Kraft CD, Levine RA, et al:: Recommendations for evaluation of the severity of native valvular regurgitation with two-dimensional and Doppler echocardiography. J Am Soc Echocardiogr 2003, I 6:777-802

14. Bader H, Garrigue S, Lafitte S, Reuter S, Jais P, Haissaguerre M, et al.: Intra-left ventricular electromechanical asynchrony. A new independent predictor of severe cardiac events in heart failure patients. J Am Coll Cardiol 2004, 43:248-256.
I5. Moonen M, Senechal M, Cosyns B, Melon P, Nellessen E, Pierard L, et al.: Impact of contractile reserve on acute response to cardiac resynchronization therapy. Cardiovasc Ultrasound 2008, 6:65.

16. Lancellotti P, Senechal M, Moonen M, Donal E, Magne J, Nellessen E, et al: Myocardial contractile reserve during exercise predicts left ventricular reverse remodelling after cardiac resynchronization therapy. Eur J Echocardiogr 2009, 10:663-8.

17. Ciampi Q, Pratali L, Citro R, Piacenti M, Villari B, Picano E: Identification of responders to cardiac resynchronization therapy by contractile reserve during stress echocardiography. Eur J Heart Fail 2009, I I:489-496.

18. Kubanek M, Malek I, Bytesnik J, Fridl P, Riedlbauchova L, Karasova L, et al: Decrease in plasma B-type natriuretic peptide early after initiation of cardiac resynchronization therapy predicts clinical improvement at 12 months. Eur J Heart Fail 2006, 8:832-840.

19. Cappola TP, Harsch MR, Jessup M, Abraham WT, Young JB, PetersenStejskal S, et al.: Predictors of remodeling in the CRT era: influence of mitral regurgitation, BNP, and gender. J Card Fail 2006, I 2:182-188.

20. Fung JW, Chan JY, Kum LC, Chan HC, Yip GW, Zhang Q, et al.: Suboptimal medical therapy in patients with systolic heart failure is associated with less improvement by cardiac resynchronization therapy. Int J Cardiol 2007, I I 5:2 I 4-2 I9.

21. Pitzalis MV, lacoviello M, Di Serio F, Romito R, Guida P, De Tommasi $E$, et al:: Prognostic value of brain natriuretic peptide in the management of patients receiving cardiac resynchronization therapy. Eur J Heart Fail 2006, 8:509-5I4.

22. Lellouche N, De Diego C, Cesario DA, Vaseghi M, Horowitz BN, Mahajan $A$, et al.: Usefulness of preimplantation B-type natriuretic peptide level for predicting response to cardiac resynchronization therapy. Am J Cardiol 2007, 99:242-246.

23. Valzania C, Gadler F, Eriksson MJ, Olsson A, Boriani G, Braunschweig $F$ : Electromechanical effects of cardiac resynchronization therapy during rest and stress in patients with heart failure. Eur J Heart Fail 2007, 9:644-650.

24. Flevari P, Theodorakis G, Paraskevaidis I, Kolokathis F, Kostopoulou $A$, Leftheriotis $D$, et al:: Coronary and peripheral blood flow changes following biventricular pacing and their relation to heart failure improvement. Europace 2006, 8:44-50.

25. Sogaard P, Egeblad H, Kim WY, Jensen HK, Pedersen AK, Kristensen $\mathrm{BO}$, et al: Tissue Doppler imaging predicts improved systolic performance and reversed left ventricular remodeling during long-term cardiac resynchronization therapy. J Am Coll Cardiol 2002, 40:723-730.

26. White JA, Yee R, Yuan X, Krahn A, Skanes A, Parker M, et al: Delayed enhancement magnetic resonance imaging predicts response to cardiac resynchronization therapy in patients with intraventricular dyssynchrony. J Am Coll Cardiol 2006, 48: $1953-1960$.

27. Henneman MM, Wall EE van der, Ypenburg C, Bleeker GB, Veire NR Van de, Marsan NA, et al.: Nuclear imaging in cardiac resynchronization therapy. J Nud Med 2007, 48:200I-20I0.

28. Chalil S, Foley PW, Muyhaldeen SA, Patel KC, Yousef ZR, Smith RE, et al:: Late gadolinium enhancement-cardiovascular magnetic resonance as a predictor of response to cardiac resynchronization therapy in patients with ischaemic cardiomyopathy. Europace 2007, 9:103|-1037.

29. Ypenburg C, Sieders A, Bleeker GB, Holman ER, Wall EE van der, Schalij Mj, et al.: Myocardial contractile reserve predicts improvement in left ventricular function after cardiac resynchronization therapy. Am Heart J 2007, I 54: I I 60- I I 65.

30. Lim P, Bars C, Mitchell-Heggs L, Roiron C, Elbaz N, Hamdaoui B, et al.: Importance of contractile reserve for CRT. Europace 2007, 9:739-743.

31. Da Costa A, Thevenin J, Roche F, Faure E, Romeyer-Bouchard C, Messier M, et al: Prospective validation of stress echocardiography as an identifier of cardiac resynchronization therapy responders. Heart Rhythm 2006, 3:406-4I3.

32. Ypenburg C, Schalij MJ, Bleeker GB, Steendijk P, Boersma E, DibbetsSchneider P, et al.: Extent of viability to predict response to cardiac resynchronization therapy in ischemic heart failure patients. J Nucl Med 2006, 47:I565-I570.

33. Tuccillo B, Muto C, lengo R, Accadia M, Rumolo S, Canciello M, et al.: Presence of left ventricular contractile reserve, evaluated by 
means of dobutamine stress-echo test, is able to predict response to cardiac resynchronization therapy. J Interv Card Electrophysiol 2008, 23:12I-126.

34. Miller WL, Hartman KA, Grill DE, Burnett JC Jr, Jaffe AS: Only large reductions in concentrations of natriuretic peptides (BNP and NT-proBNP) are associated with improved outcome in ambulatory patients with chronic heart failure. Clin Chem 2009, 55:78-84.

35. Yu CM, Bleeker GB, Fung JW, Schalij MJ, Zhang Q, Wall EE van der, et al: Left ventricular reverse remodeling but not clinical improvement predicts long-term survival after cardiac resynchronization therapy. Circulation 2005, I | 2: I580-I586.

Publish with Bio Med Central and every scientist can read your work free of charge

"BioMed Central will be the most significant development for disseminating the results of biomedical research in our lifetime. "

Sir Paul Nurse, Cancer Research UK

Your research papers will be:

- available free of charge to the entire biomedical community

- peer reviewed and published immediately upon acceptance

- cited in PubMed and archived on PubMed Central

- yours - you keep the copyright
BioMedcentral 